Religare, ISSN: 19826605, v.15, n.2, dezembro de 2018, p.704-705.

\title{
Nominata
}

\section{Pareceristas internos}

Profa. Dra. Ana Paula Rodrigues Cavalcanti

Prof. Dr. Carlos André Macedo Cavalcanti

Profa. Dra. Dilaine Soares Sampaio

Prof. Dr. Fabrício Possebon

Prof. Dr. Johnni Langer

Prof. Dr. Lusival Barcellos

Profa. Dra. Maria Lucia Abaurre Gnerre

Prof. Dr. Matheus Da Cruz E Zica

\section{Pareceristas externos - ad hoc}

Profa. Dra. Ana Claudia Figueroa

Prof. Dr. Augusto César De Araújo

Profa. Dra. Claudete Beise Ulrich

Profa. Dra. Daniela Cordovil

Prof. Dr. Eduardo Chagas

Prof. Dr. Emerson José Sena

Prof. Dr. Fabrício Possebon

Prof. Dr. Gedeon Alencar

Prof. Dr. Gilbraz Aragão

Prof. Dr. Jaci Souza Candiotto

Prof. Dr. Leandro Duarte Rust

Prof. Dr. Leandro Pereira Gonçalves 
Religare, ISSN: 19826605, v.15, n.2, dezembro de 2018, p.704-705.

Prof. Dr. Luciano Silva

Profa. Dra. Maria Anita Vieira Lustosa

Profa. Dra. Maristela Andrade

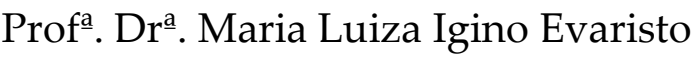

Profa. Dra. Márcia Gardênia Lustosa Pires

Prof. Dr. Marcos Vinícius De Freitas Reis

Profa. Dra. Nilza Menezes

Prof. Dr. Rangel De Oliveira Medeiros

Prof. Dr. Rodrigo Rosal

Profa. Dra. Rosângela Siqueira Da Silva

Profa. Dra. Sandra Duarte De Souza

Profa. Dra. Suzana Coutinho

Prof. Dr. Telmo Vieira

Prof. Dr. Volney Berkenbrock

Prof. Dr. Yllan de Mattos

Profa. Dra. Zuleica Campos 